\title{
BIOLOGICAL AND CHEMICAL INHIBITION OF LIGNO-CELLULOSE DECAY BY WHITE ROT BASIDIOMYCETES
}

\author{
J. ANTHEUNISSE AND J. BUREMA \\ Laboratory of Microbiology, Agricultural University, \\ Wageningen, The Netherlands
}

(Received July 30, 1982)

The white rot decay of coconut fibres caused by pure cultures of the basidiomycetes Trametes versicolor (L. ex Fr.) Lloyd and Stereum rugosum (Pers. ex Fr.) Fr. was strongly inhibited by the previous inoculation of cellulolytic fungi belonging to the ascomycetes and Fungi imperfecti. Generally, the total white rot decay was hardly or moderately inhibited when the basidiomycete was inoculated first. The cause of this biological inhibition is discussed. Another aspect of the present study is the toxicity of copper and zinc ions on the white rot decay of coir caused by the basidiomycetes mentioned. The effect of copper and zinc ions on coir degradation in non-sterilized soil is also demonstrated.

The decomposition of the ligno-cellulose of coconut fibres, as used around plastic drain pipes, may be caused by basidiomycetes of the genera Stereum and Trametes within 3-5 months (1). During these experiments it was observed that the white rot decay of the fibres was inhibited when cellulolytic fungi belonging to the ascomycetes or Fungi imperfecti had contaminated the culture. Intensive study of this phenomenon showed that several cellulolytic non-basidiomycetes that probably are able to penetrate the coconut fibres (2) may inhibit the white rot decay of coconut fibres. A similar effect by Trichoderma viride, for example on wood-destroying basidiomycetes, was reported by Hulme and SHIElds (3) and TichY (4).

In the present study the lignin-cellulose decay by a pure culture of the basidiomycetes mentioned was also inhibited by the previous treatment of coconut fibres with copper or zinc salts. The inhibiting effect of copper and zinc ions on the decay of jute in loamy soil was proved already by ELKIN and WhiTE (5). The toxic effect of copper or zinc ions on fungi has been reported several times $(6-8)$ and their inhibiting effect on the growth of wood-destroying fungi is well-known $(9,10)$. 


\section{MATERIALS AND METHODS}

Biological inhibition of white rot decay. 1. An experiment was carried out in Erlenmeyer flasks of $500 \mathrm{ml}$ capacity as described by ANTHEUNISSE (1). Each flask containing from bottom to top, water, air, coconut fibres and approximately $100 \mathrm{~g}$ soil (a mixture of clay and sandy soil of $1: 1 ; \mathrm{pH} 7.2$ ) was sterilized and inoculated with a fungus that may partly decompose the lignin-cellulose complex (11) and with the basidiomycete Trametes versicolor (L. ex Fr.) Lloyd CBS 47172 (T15). Both cultures were inoculated simultaneously. After 16 weeks at $25^{\circ}$ the coir mats were photographed (Fig. 1) and the strength of the fibres was estimated (1) in duplicate and calculated as loss of strength against that of fresh fibres. Names of the fungi and tensile strength are given in Table 1.

2. In a second experiment similar to the first one, an incubation period of two weeks was inserted between the inoculation of the cellulolytic fungi and that of the basidiomycetes. In the experiment of Fig. 2A and column A of Table 2, the coir mats were inoculated with one of the fungi recorded in Table 2 at 2 weeks before the inoculation with the basidiomycetes Trametes versicolor (T15). In this case the various fungi were able to penetrate the coconut fibres before the basidiomycete. In the experiment of Fig. 2B and column B of Table 2 the coconut fibres were first inoculated with the basidiomycete that had a 2 weeks start of the

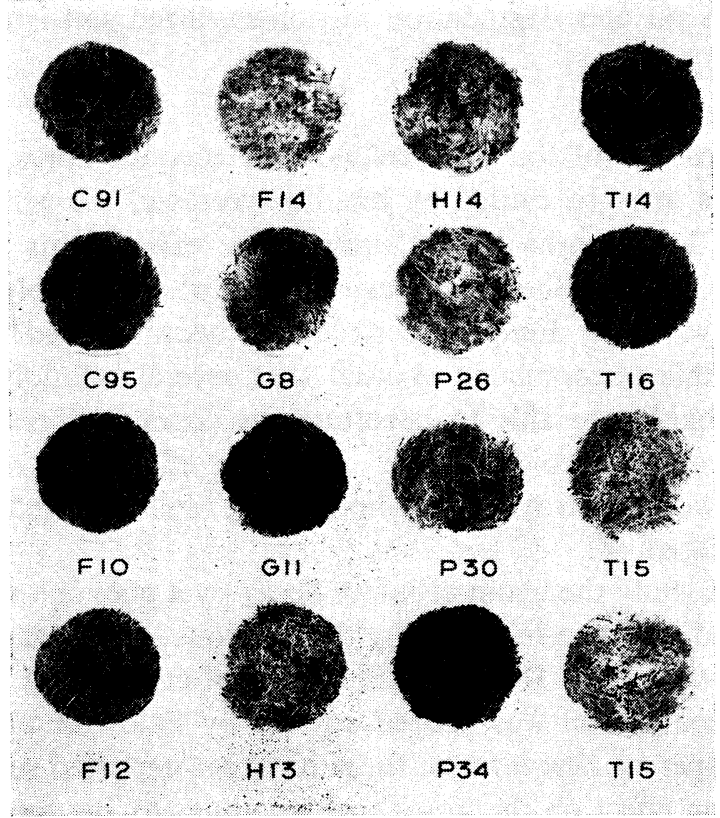

Fig. 1. White rot decay of coconut fibres by the basidiomycete Trametes versicolor (T15) as affected by other cellulolytic fungi, inoculated simultaneously with the basidiomycete. Incubation at $25^{\circ}$ for 16 weeks. The names of the fungi are given in Table 1 . 
Table 1. Inhibition of white rot decay of coconut fibres by cellulolytic fungi inoculated simultaneously with the basidiomycete Trametes versicolor (T15).

\begin{tabular}{lc} 
& Loss of strength (\%) \\
\hline Cladorrhinum foecundissimum Sacc. \& March. C91 & $54 \pm 1$ \\
Chaetomium globosum Kunze ex. Fr. C95 & $44 \pm 0$ \\
Fusarium culmorum (W. G. Smith) Sacc. F10 & $39 \pm 7$ \\
Fusarium flocciferum Corda F12 & $33 \pm 3$ \\
Fusarium oxysporum Schlecht ex Fr. F14 & $90 \pm 2$ \\
Gliocladium roseum Bain. G8 & $-a$ \\
Gliocladium virens Miller et al. G11 & $41 \pm 1$ \\
Humicola cf. nigrescens Omvik H13 & $77 \pm 1$ \\
Phialophora malorum (Kidd \& Beaumont) McColloch P26 fuscoatra Traaen H14 & $94 \pm 4$ \\
Penicillium sp. P30 & $95 \pm 3$ \\
Penicillium simplicissimum (Oudem.) Thom P34 & $87 \pm 1$ \\
Trichoderma viride Pers. ex S. F. Gray T14 & $23 \pm 7$ \\
Trichoderma harzianum Rifai T16 & $11 \pm 4$ \\
Trametes versicolor (L. ex Fr.) Lloyd T15=(CBS 47172) & $38 \pm 4$ \\
Trametes versicolor (L ex Fr.) Lloyd T15=(CBS 47172) & $94 \pm 1$ \\
\hline
\end{tabular}

a The decay of this coir mat was locally inhibited. Data on the loss of strength are therefore omitted.

other fungi. Sixteen weeks after the addition of the basidiomycetes both series were harvested. The names of the fungi and the tensile strength are summarized in Table 2.

3. In a third experiment the white rot basidiomycete Stereum rugosum (Pers. ex Fr.) Fr. S55 (CBS 47472) was used. The cellulolytic fungi were inoculated 2 weeks before the basidiomycete (Fig. 3A and column A of Table 3) or 2 weeks after the addition of the white rot fungus (Fig. 3B and column B of Table 3). Also in this case both series were harvested 16 weeks after inoculation of the basidiomycetes. The names of the fungi and the tensile strength are given in Table 3.

4. The production of toxin(s) by the aforesaid fungi affecting the two basidiomycetes used in this study was checked on malt agar plates and in malt extract cultures. In both cases the malt extract contained $0.2 \% \mathrm{CaCO}_{3}(\mathrm{pH} 6.5)$. A fungus and one of the basidiomycetes were inoculated on the malt agar plates with a $7 \mathrm{~cm}$ distance between them. The development of a zone of inhibition between the two fungi was checked. Acid production was detected by dissolving $\mathrm{CaCO}_{3}$.

In the liquid medium test, Erlenmeyer flask containing $50 \mathrm{ml}$ malt extract supplied with $0.2 \% \mathrm{CaCO}_{3}$ were inoculated with one of the fungi and incubated at $25^{\circ}$ until sufficient growth was attained (5-10 days). The culture was filtered through a porcelain Chamberland filter $5 \mathrm{~L} 5$ or $5 \mathrm{~L} 3$ and the filtrate was transferred to sterile culture tubes which were inoculated with one of the two basidiomycetes. As a control the basidiomycetes were inoculated in the original malt extract. 


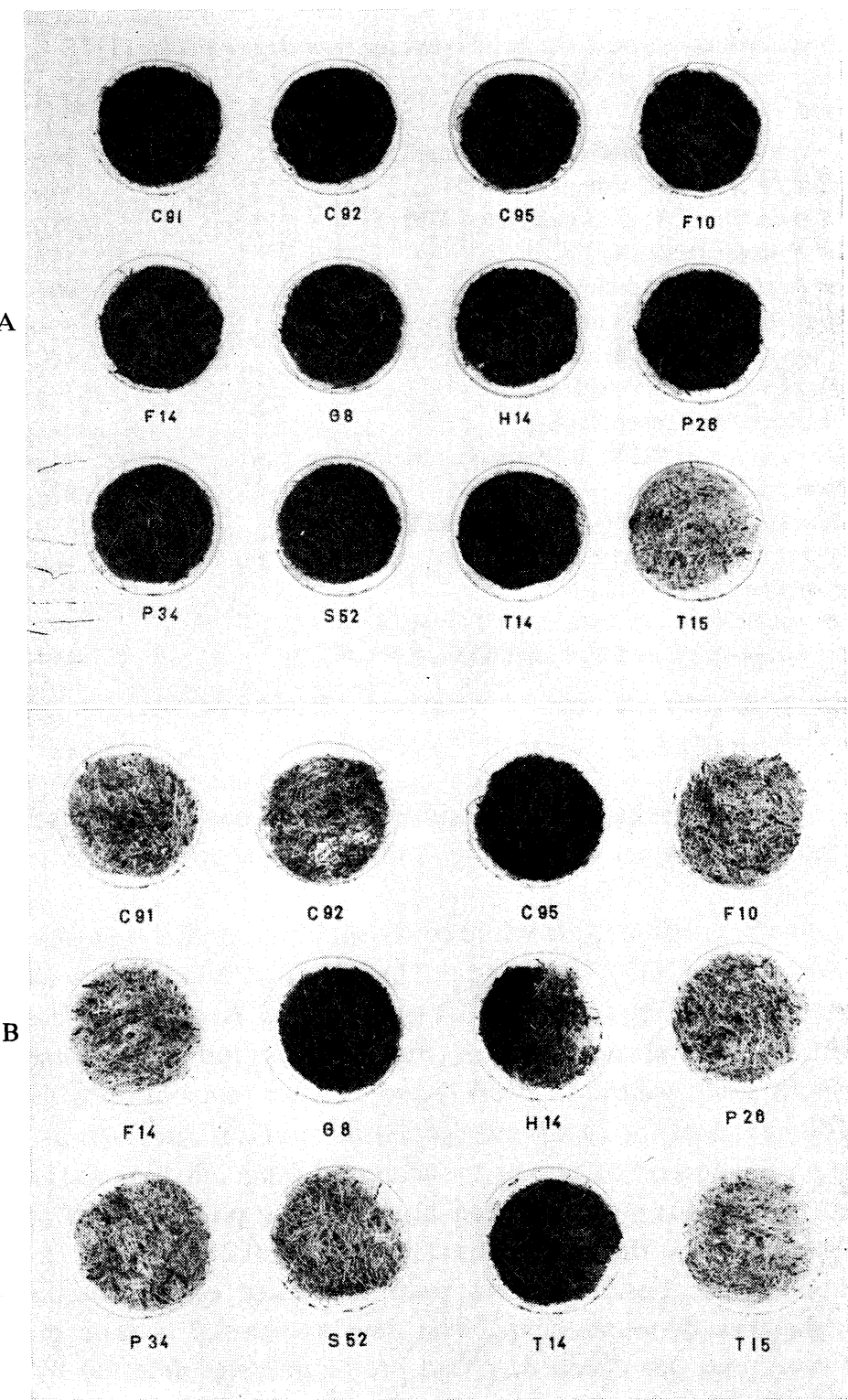

Fig. 2. White rot decay of coconut fibres by the basidiomycete Trametes versicolor (T15) as affected by other cellulolytic fungi, inoculated 2 weeks before (A) and 2 weeks after (B) the basidiomycete. Incubation at $25^{\circ}$ for 16 weeks of T15 in both series. The names of the fungi are given in Table 2 . 


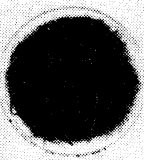

c 91

A

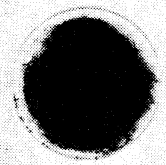

514

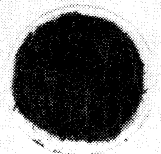

34

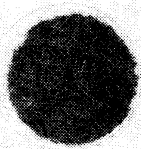

c 21

B

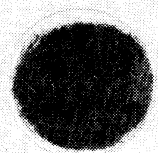

F 14

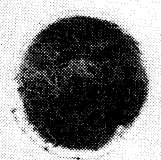

P 34

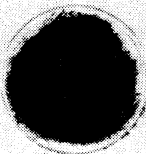

$\mathrm{C} 82$

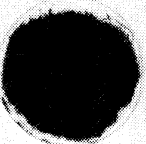

Q 8

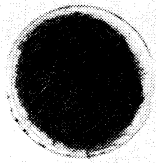

$\$ 52$

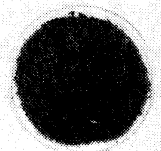

C 92

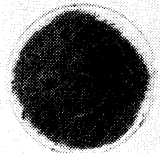

08

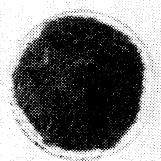

S52

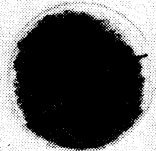

$\mathrm{cQ5}$

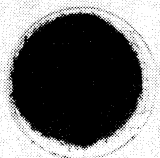

H14

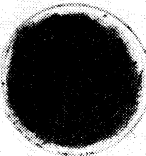

716

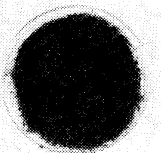

C 95

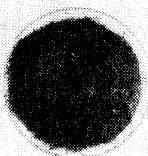

HIf

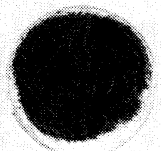

114

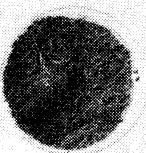

F10

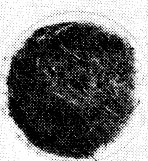

P2 6
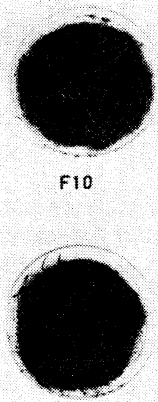

P 26
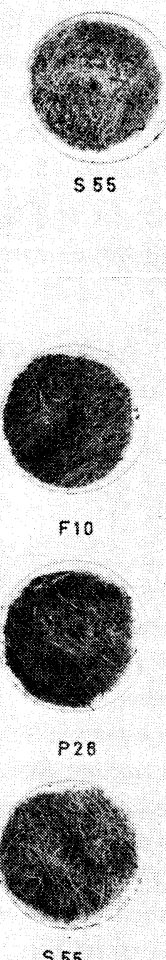

Fig. 3. White rot decay of the basidiomycete Stereum rugosum (S55) as affected by other cellulolytic fungi, inoculated 2 weeks before (A) and 2 weeks after (B) the basidiomycete. Incubation at $25^{\circ}$ for 16 weeks of S55 in both series. The names of the fungi are given in Table 3. 
Table 2. Inhibition of white rot decay of coconut fibres by cellulolytic fungi inoculated 2 weeks before (A) or after (B) the basidiomycete Trametes versicolor was inoculated. ${ }^{a}$

\begin{tabular}{lcc}
\hline & \multicolumn{2}{c}{ Loss of strength (\%) } \\
\cline { 2 - 3 } & A & B \\
\hline Cladorrhinum foecundissimum Sacc. \& March. C91 & $48 \pm 2$ & $87 \pm 6$ \\
Cladorrhinum sp. II C92 & $51 \pm 1$ & $93 \pm 1$ \\
Chaetomium globosum Kunze ex Fr. C95 & $36 \pm 4$ & $39 \pm 3$ \\
Fusarium culmorum (W. G. Smith) Sacc. F10 & $41 \pm 1$ & $91 \pm 1$ \\
Fusarium oxysporum Schlecht ex Fr. F14 & $26 \pm 4$ & $84 \pm 1$ \\
Gliocladium roseum Bain. G8 & $26 \pm 1$ & $20 \pm 4$ \\
Humicola fuscoatra Traaen H14 & $59 \pm 4$ & -6 \\
Phialophora malorum (Kidd \& Beaumont) McColloch P26 & $28 \pm 3$ & $93 \pm 3$ \\
Penicillium simplicissimum (Oudem.) Thom P34 & $40 \pm 7$ & $95 \pm 2$ \\
Staphylotrichum coccosporum Meyer \& Nocit S52 & $45 \pm 3$ & $93 \pm 3$ \\
Trichoderma viride Pers. ex S.F. Gray T14 & $14 \pm 2$ & $44 \pm 5$ \\
Trametes versicolor (L. ex Fr.) Lloyd T15=(CBS 47172) & $93 \pm 3$ & $93 \pm 2$ \\
\hline
\end{tabular}

$a$ In both series (A and B) the basidiomycete was incubated for 16 weeks at $25^{\circ}$.

$b$ The decay of this coir mat was locally inhibited. Data on the loss of strength are therefore omitted.

Table 3. Inhibition of white rot decay of coconut fibres by cellulolytic fungi inoculated 2 weeks before (A) or after (B) the basidiomycete Stereum rugosum was inoculated. ${ }^{a}$

\begin{tabular}{lcc}
\hline & \multicolumn{2}{c}{ Loss of strength (\%) } \\
\cline { 2 - 3 } & A & B \\
\hline Cladorrhinum foecundissimum Sacc. \& March. C91 & $38 \pm 3$ & $51 \pm 4$ \\
Cladorrhinum sp. II C92 & $49 \pm 3$ & $49 \pm 3$ \\
Chaetomium globosum Kunze ex Fr. C95 & $29 \pm 1$ & $42 \pm 5$ \\
Fusarium culmorum (W. G. Smith) Sacc. F10 & $32 \pm 2$ & $48 \pm 3$ \\
Fusarium oxysporum Schlecht ex Fr. F14 & $22 \pm 3$ & $23 \pm 5$ \\
Gliocladium roseum Bain. G8 & $20 \pm 4$ & $26 \pm 3$ \\
Humicola fuscoatra Traaen H14 & $49 \pm 2$ & $50 \pm 1$ \\
Phialophora malorum (Kidd \& Beaumont) McColloch P26 & $24 \pm 8$ & $39 \pm 2$ \\
Penicillium simplicissimum (Oudem). Thom P34 & $27 \pm 2$ & $35 \pm 1$ \\
Staphylotrichum coccosporum Meyer \& Nocit S52 & $23 \pm 5$ & $48 \pm 1$ \\
Trichoderma viride Pers. ex S. F. Gray T14 & $25 \pm 3$ & $25 \pm 4$ \\
Stereum rugosum (Pers. ex Fr.) Fr. S55=(CBS 47472) & $85 \pm 2$ & $76 \pm 2$ \\
\hline
\end{tabular}

${ }^{a}$ In both series (A and B) the basidiomycete was incubated for 16 weeks at $25^{\circ}$.

The lack of growth of the basidiomycetes on the, not exhausted, culture filtrate of the fungi indicated the harmful effect of toxin(s) (Table 4).

Chemical inhibition of white rot decay. 1. The chemical inhibition of white rot decay was achieved by the immersion of the coir mats for 3 days in saturated copper or zinc sulphate at room temperature. The high salt concentration was used because of the assumed low moisture absorbing capacity of coconut fibres. 
Table 4. Growth of the basidiomycetes Trametes versicolor (T15) and Stereum rugosum (S55) on culture filtrates from different cellulolytic fungi after 8 days incubation at $25^{\circ}$.

\begin{tabular}{lcc}
\hline & $\begin{array}{c}\text { Trametes } \\
\text { versicolor }\end{array}$ & $\begin{array}{c}\text { Stereum } \\
\text { rugosum }\end{array}$ \\
\hline Cladorrhinum foecundissimum Sacc. \& March. C91 & $+^{a}$ & + \\
Cladorrhinum sp. II C92 & + & + \\
Chaetomium globosum Kunze ex Fr. C95 & + & + \\
Fusarium culmorum (W. G. Smith) Sacc. F10 & + & + \\
Fusarium flocciferum Corda F13 & + & + \\
Fusarium oxysporum Schlecht. ex Fr. F14 & + & - \\
Gliocladium roseum Bain. G8 & + & + \\
Gliocladium virens Miller et al. G11 & + & + \\
Humicola cf. nigrescens Omvik H13 & + & + \\
Humicola fuscoatra Traaen H14 & + & + \\
Phialophora malorum (Kidd \& Beaumont) McColloch P26 & + & + \\
Penicillium sp. P30 & $+( \pm)^{b}$ & $+( \pm)^{b}$ \\
Penicillium simplicissimum (Oudem.) Thom P34 & $+(-)^{b}$ & $+(-)^{b}$ \\
Staphylotrichum coccosporum Meyer \& Nocit S52 & + & + \\
Trichoderma viride Pers. ex S. F. Gray T14 & - & - \\
Trichoderma harzianum Rifai T16 & - & - \\
\hline
\end{tabular}

$a+$ denotes growth, \pm slight and - no growth.

$b$ Culture filtrates without added calcium carbonate in parentheses.

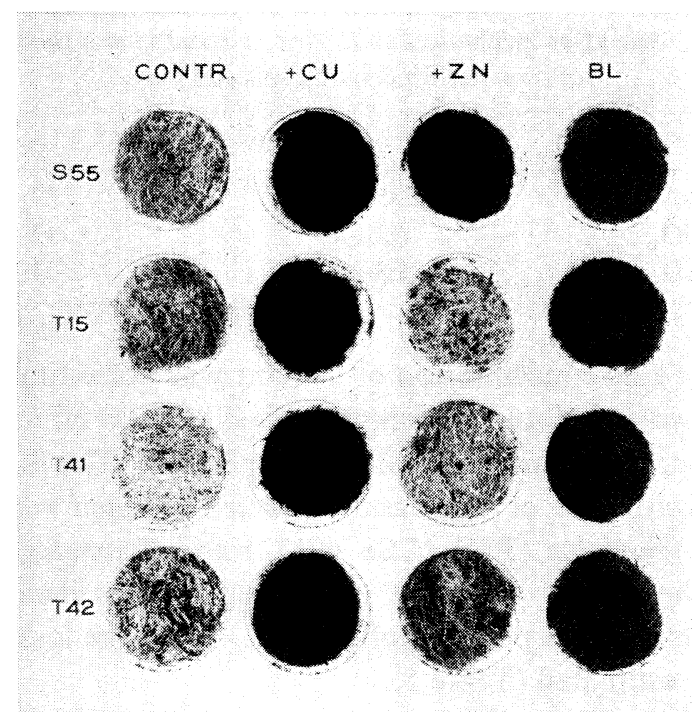

Fig. 4. Inhibition by copper and zinc ions of white rot decay of coconut fibres. The fibres were inoculated with Stereum rugosum (S55) and Trametes versicolor (T15, T41 and T42). The blanks (BL) were not inoculated. The incubation period was 16 weeks at $25^{\circ}$. 
Table 5. Inhibition by copper and zinc ions of white rot decay of coconut fibres.

\begin{tabular}{lccc}
\hline \multirow{2}{*}{ Basidiomycetes } & \multicolumn{3}{c}{ Loss of strength (\%) } \\
\cline { 2 - 4 } & Control & $+\mathrm{CuSO}_{4}$ & $+\mathrm{ZnSO}_{4}$ \\
\hline Stereum rugosum S55 & $79 \pm 4$ & $29 \pm 1$ & $28 \pm 1$ \\
Trametes versicolor T15 & $94 \pm 1$ & $35 \pm 6$ & $95 \pm 1$ \\
Trametes versicolor T41 & $99 \pm 1$ & $41 \pm 1$ & $83 \pm 4$ \\
Trametes versicolor T42 & $86 \pm 7$ & $39 \pm 4$ & $77 \pm 2$ \\
\hline
\end{tabular}

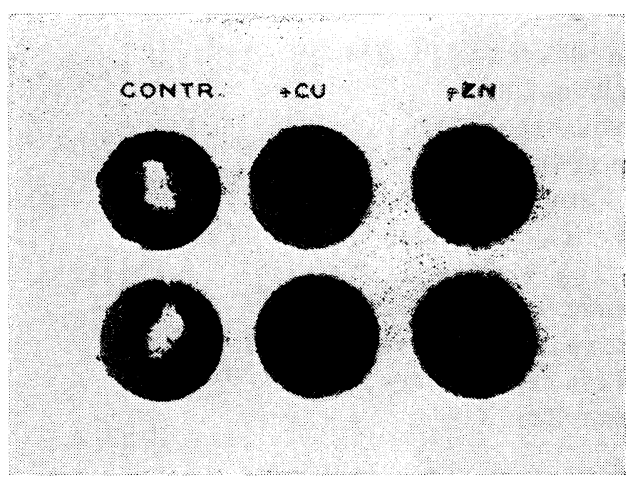

Fig. 5. Inhibition by copper and zinc ions of coir decomposition after 11 months of incubation at $25^{\circ}$ in a mixture of non-sterilized sandy soil and clay.

Table 6. Inhibition of the decay of coconut fibres, impregnated by copper and zinc ions, after incubation at $25^{\circ}$ for 11 months in a mixture of non-sterilized sandy soil and clay.

\begin{tabular}{lll}
\hline & \multicolumn{2}{c}{ Loss of strength (\%) } \\
\hline Control & $81 \pm 1$ & $87 \pm 2$ \\
$+\mathrm{CuSO}_{4}$ & $32 \pm 4$ & $43 \pm 1$ \\
$+\mathrm{ZnSO}_{4}$ & $68 \pm 2$ & $73 \pm 1$ \\
\hline
\end{tabular}

The final copper or zinc concentration of the coir was not estimated. The experiment was carried out as before in Erlenmeyer flasks of $500 \mathrm{ml}$ capacity containing, from bottom to top, water, air, coconut fibres and soil. The flasks were sterilized twice, inoculated with one of the basidiomycetes Stereum rugosum (S55) (CBS 47472); Trametes versicolor (T15) (CBS 47172) and Trametes versicolor, strains T41 and T42. The blanks were not inoculated. After incubation at $25^{\circ}$ for 16 weeks the coir mats were photographed (Fig. 4) and the loss of strength of the coconut fibres was estimated (Table 5).

2. The inhibition of coir-destroying microorganisms (probably fungi) in soil by copper and zinc ions was tested in $2 l$ jars, containing from bottom to top, water, air, coconut fibres and about $800 \mathrm{~g}$ of a mixture of equal amounts of sandy soil and clay (12). The coir mats were treated with copper and zinc sulphate as 
described before. After 11 months of incubation at $25^{\circ}$, photographs were made of the coir mats (Fig. 5); tensile strengths of the fibres are summarized in Table 6.

\section{RESULTS}

Biological inhibition of white rot decay

1. When a cellulolytic fungus and the basidiomycete Trametes versicolor (T15) were inoculated simultaneously, the white rot decay of the coir was often retarded by the presence of the fungus. Strong or moderate inhibition of white rot decay was brought about by Cladorrhinum foecundissimum C91, Chaetomium globosum C95, Fusarium culmorum F10, Fusarium flocciferum F12, Gliocladium virens G11, Penicillium simplicissimum P34, Trichoderma viride T14 and Trichoderma harzianum T16. The dark-brown colour of the coir (Fig. 1) and the scanty or moderate loss of strength of the fibres (Table 1) indicate inhibition of white rot decay by most of the fungi tested.

Fusarium oxysporum F14, Humicola cf. nigrescens H13, Humicola fuscoatra H14, Penicillium species P30 and Phialophora malorum P26 showed little or no inhibition of the white rot decay. Gliocladium roseum G8 exhibited a partial white rot decay of the coir mat so that the estimation of the loss of strength of the fibres was unreliable.

2. In this experiment the cellulolytic fungi were inoculated two weeks before or after the addition of the basidiomycete Trametes versicolor (T15). Inhibition of white rot decay by the cellulolytic fungi tested was quite common when these fungi were inoculated two weeks earlier than the white rot fungus. In this case the strongest inhibition was caused by Chaetomium globosum C95, Fusarium oxysporum F14, Gliocladium roseum G8, Phialophora malorum P26 and Trichoderma viride T14 (Fig. 2A and column A of Table 2). When Trametes versicolor T15 was inoculated two weeks earlier than the other cellulolytic fungi, the inhibition of white rot decay was less pronounced. Under these circumstances, only Chaetomium globosum (C95), Gliocladium roseum (G8) and Trichoderma viride T14 considerably retarded the white rot decay (Fig. 2B and column B of Table 2).

3. A similar experiment carried out with the basidiomycete Stereum rugosum S55 demonstrated strong inhibition of white rot decay by all the cellulolytic fungi when inoculated two weeks before the inoculation of the white rot fungus (Fig. 3A and column A of Table 3). Even when Stereum rugosum (S55) was inoculated first, the white rot decay of the coconut fibre was retarded in all cases. Especially Fusarium oxysporum (F14), Gliocladium roseum (G8) and Trichoderma viride (T14) considerably retarded the white rot decay in this situation (Fig. 3B and column B of Table 3).

4. When malt extract agar plates were used, the fungi produced no toxins adversely affecting the two basidiomycetes. In all combinations the fungi developed normally and there was no inhibition of the growth of the basidiomycete by 
toxin formation. Strains of the genus Penicillium P30 and P34 dissolved the calcium carbonate in the agar medium, indicating acid formation. Nearly all tubes with culture filtrates derived from malt extract cultures of the various fungi exhibited growth of the two basidiomycetes Trametes versicolor T15 and Stereum rugosum S55. The culture filtrates of Trichoderma viride T14 and Trichoderma harzianum T16, however, probably contained toxin(s) that inhibited the growth of both white rot fungi. The culture filtrate of Fusarium oxysporum F14 inhibited only the growth of Stereum rugosum (Table 4).

The culture filtrates of only the Penicillium species P30 and P34 inhibited growth of the basidiomycetes when $\mathrm{CaCO}_{3}$ was omitted. The acid formation, already observed in the malt agar plates with $\mathrm{CaCO}_{3}$, apparently was the cause of this inhibition. After 8 days of incubation at $25^{\circ}$, however, the growth of the basidiomycetes started in spite of the acid produced.

\section{Chemical inhibition of white rot decay}

1. The chemical inhibition of white rot decay of coconut fibres, by copper and zinc ions is demonstrated in Fig. 4. The white rot decay was caused by Stereum rugosum S55 or by one of the three strains of Trametes versicolor, T15, T41 and T42 from the laboratory collection. The white rot caused by Stereum rugosum was clearly depressed by both copper and zinc sulphate. The three strains of Trametes versicolor, however, were strongly inhibited by only copper ions. The fibres of the different coir mats exhibited a loss of strength that confirms the visual observations (Table 5).

2. The decomposition of coir by soil microorganisms was also retarded by copper and zinc ions in experiments with a mixture of nonsterilized clay and sandy soil $(1: 1)$. Coir mats which had not been immersed in saturated copper or zinc sulphate solutions were largely decomposed after incubation at $25^{\circ}$ for 11 months. Fibres in the centre of these coir mats, which had been pressed between the soil and the bottom of the flower pot, were already entirely decayed (Fig. 5). The loss of strength of the remaining fibres was high as contrasted with that of the coir treated with copper ions. The inhibition of coir decomposition after treatment with zinc sulphate was less pronounced. Only a small decline in the loss of strength was found (Table 6).

\section{DISCUSSION}

In this study it is shown that a number of cellulolytic fungi may retard the ligno-cellulose decay of coconut fibres caused by basidiomycetes. The biological control of white rot decay of wood by two other cellulolytic fungi was reported earlier by Hulme and SHIELdS (3). They found a considerable reduction of the loss of weight of birch sapwood after a 4 month incubation period when one of the basidiomycetes Polyporus adustus, Willd. ex Fr. Polyporus hirsutus (Wulf. ex Fr.) 
Pilat or Polyporus versicolor (synonym of Trametes versicolor (L. ex Fr.) Lloyd) was inoculated together with Trichoderma viride or Gliocladium viride. This phenomenon may be explained by the suggestion of those authors that some fungi are able to colonize wood chiefly by utilizing the non-structural carbohydrates. Basidiomycetes would not readily invade wood when a different cellulolytic fungus had penetrated into the material and had utilized the non-structural carbohydrates. Trichoderma viride, the most readily growing fungus on malt agar, provided the best protection against decay by the basidiomycetes. The production by such a fungus of toxin(s) adversely affecting the growth of the basidiomycetes was not detected by Hulme and Shields (3) with malt agar plate cultures.

Toxin(s), produced by the cellulolytic fungi, retarding the development of the basidiomycetes Trametes versicolor and Stereum rugosum also were not detected in the present study when both types of organism were grown on malt agar plates. However, some fungi produced toxin(s) when malt extract supplied with $\mathrm{CaCO}_{3}$ was used as the growth medium. Trichoderma viride, which produced toxin(s) inhibiting the growth of $T$. versicolor and $S$. rugosum, protected coconut fibres against white rot decay by both basidiomycetes mentioned above, when inoculated together with or earlier than the basidiomycetes (Tables 1-3). Trichoderma harzianum also produced toxin(s) and moderately inhibited white rot when inoculated together with Trametes versicolor (Table 1).

Fusarium oxysporum, which produced toxin(s) against the development of Stereum rugosum, inhibited the white rot decay even when inoculated after the basidiomycete (Table 3). It did not seriously delay the decay of coconut fibres by Trametes versicolor when inoculated together with or after this basidiomycete (Tables 1 and 2).

Penicillium simplicissimum, which strongly retarded the development of the two basidiomycetes, probably by producing acids, strongly or moderately inhibited white rot decay when inoculated with or before the basidiomycetes (Tables 1-3). The production of mycotoxin(s) by Trichoderma viride, Gliocladium roseum and Gliocladium virens, used in the present work, has been reported by BRIAN and McGowan (13), Brian et al. (14), and Aluko and Hering (15). However, the toxin(s) of these Gliocladium species did not affect the basidiomycetes used in the present study. Because only a few of the many cellulolytic fungi that inhibited white rot decay produced toxin or acids active against the basidiomycetes studied in the present work, it may be concluded that in most cases the biological inhibition by cellulolytic fungi of white rot of coconut fibres and wood is based on nutrient competition only. But toxin and acid formation may play an additional role in this competition. The observation that the previously inoculated basidiomycete Trametes versicolor completed the white rot decay, in spite of the presence of the cellulolytic fungus, is an argument for this suggestion (Table 2).

The inhibition of white rot is related to the respective times of inoculation of the cellulolytic fungus and the basidiomycete. When the cellulolytic fungus 
and Trametes versicolor were inoculated simultaneously, 8 out of the 13 fungi tested significantly inhibited white rot (Fig. 1 and Table 1).

Inoculation with the basidiomycete 2 weeks earlier than inoculation with the cellulolytic fungi brought about clear retardation of white rot by Trametes versicolor with 3 out of 10 fungi tested (Fig. 2B and column B of Table 2). However, when the cellulolytic fungi were inoculated 2 weeks before the basidiomycete, all 11 fungi tested strongly or moderately inhibited the white rot caused by Trametes versicolor (Fig. 2A and column A of Table 2).

White rot of coconut fibres by Stereum rugosum is easier to suppress than that by Trametes versicolor. Even when Stereum rugosum was added 2 weeks earlier than the cellulolytic fungi, strong or moderate inhibition of white rot occurred, which was probably caused by slow growth of the basidiomycete through the soil layer. The reverse inoculation sequence led mostly to stronger white rot inhibition.

Although the biological control of white rot caused by pure cultures of two basidiomycetes was demonstrated under laboratory conditions, the influence of the tested fungi on the ligno-cellulose decomposition of coconut fibres in soil is still unknown. Whether or not the life of the coir wrapper around drain pipes under field conditions can be extended in this way is uncertain. Results of experiments in soil with coir, previously treated with each of the cellulolytic fungi, are not yet available.

The chemical inhibition with copper ions of white rot decay caused by pure cultures of Trametes versicolor and Stereum rugosum was clearly demonstrated. Coir treated with zinc sulphate was still susceptible to white rot degradation by Trametes versicolor, but not by Stereum rugosum (Fig. 4 and Table 5). The attack of organisms present in added soil on coconut fibres previously treated with copper and zinc sulphate is also demonstrated. The centres of the untreated coir mats, pressed by the soil on the bottom of the turned flowerpot, were wholly decomposed and the remaining fibres were weakened. However, the typical colour of white rot is seldom observed after incubation in non-sterilized soil. The treatment with copper sulphate inhibited the coir decay best (Fig. 5 and Table 6). It may be expected that the durability of the coir wrapper around plastic drains under field circumstances can be extended by this treatment.

The assistance of Mrs. de Bruin-Tol, Mr. A. Wessels and the helpful advice of the Centraal Bureau voor Schimmelcultures, Baarn, Holland is gratefully acknowledged.

\section{REFERENCES}

1) J. Antheunisse, J. Gen. Appl. Microbiol., 26, 167 (1980).

2) J. Antheunisse, J. Gen. Appl. Microbiol., 25, 273 (1979).

3) M. A. Hulme and J. K. Shields, Nature, 227, 300 (1970).

4) V. Tichy, Drev. výjsk., 20, 37 (1975). 
5) H. A. Elkin and W. A. S. White, J. Text. Inst., 30, 340 (1939).

6) W. H. N. PAton and K. BudD, J. Gen. Microbiol., 72, 173 (1972).

7) I. S. Ross, Trans. Br. Mycol. Soc., 64, 175 (1975).

8) R. L. Starkey, J. Gen. Microbiol., 78, 217 (1973).

9) E. W. B. DA Costa, Nature, 183, 910 (1959).

10) G. Y. Young, Forest Disease Laboratory Report No. 2223. United States Department of Agriculture, Forest Service, Beltville, Maryland (1961).

11) J. Antheunisse, J. Gen. Appl. Microbiol., 27, 435 (1981).

12) J. Antheunisse, Plant Soil, 51, 145 (1979).

13) P. W. Brian and J. C. McGowan, Nature, 156, 144 (1945).

14) P. W. Brian, P. J. Curtis, S. R. Howland, E. G. Jefferys, and H. Raudnitz, Experienta, 7, 266 (1951).

15) M. O. Aluko and T. F. Hering, Trans. Br. Mycol. Soc., 55, 173 (1970). 